\title{
The impact of electrochemical assistance on the microturning process
}

\author{
Sebastian Skoczypiec $^{1} \cdot$ Marcin Grabowski $^{1}$ • Adam Ruszaj ${ }^{1}$
}

Received: 28 April 2015 / Accepted: 29 December 2015 / Published online: 12 January 2016

(C) The Author(s) 2016. This article is published with open access at Springerlink.com

\begin{abstract}
In the paper, the concept of an electrochemically assisted microturning process is presented. This is a hybrid machining process in which microcutting directly removes the material while electrochemical passivation changes the conditions of material removal. A test stand was designed and built to investigate this process. The experimental part includes a discussion of the research methodology and a comparison of the straight turning results in the case of machining 1.4301 stainless steel without and with electrochemical assistance. The change of the main cutting force resulting from electrochemical assistance was selected as the main investigated technological factor. Based on this study, we can state that in the case analyzed here (when only passivation is taken into account), electrochemical assistance brings significant benefits when the depth-of-cut is $\leq 1 \mu \mathrm{m}$.
\end{abstract}

Keywords Micromachining - Microturning . Hybrid machining $\cdot$ Electrochemical assistance

\section{Introduction}

The production of microparts is a dynamically developing area in manufacturing technologies. The same as in macromanufacturing, advanced materials play an increasingly important role in the shaping of microparts. Improved thermal, chemical, and mechanical properties of a given

Sebastian Skoczypiec

skoczypiec@m6.mech.pk.edu.pl

1 Institute of Production Engineering, Cracow University of Technology, Al. Jana Pawla II 37, 31-864 Krakow, Poland material give substantial benefits to product design and performance; however, they also make traditional machining processes inefficient economically or impossible to apply in general. Therefore, special attention is paid to the application of microcutting and unconventional processes, especially in the group of methods dedicated to machining technological equipment, micro-electro-mechanical systems (MEMS) parts, functional prototypes, and tools for micro-casting and micro-forming.

For the production of micro-parts made of materials that are difficult to cut and have free-form surfaces a rational way of shaping is electrochemical (ECM) and electrodischarge (EDM) machining [10, 12, 18]. In these processes, material removal is not dependent on the machined material's mechanical properties. In ECM, material is removed atom by atom as a result of the dissolution process according to Faraday's and Ohm's laws. The metal removal rate of this process and the surface quality of the machined surface are very high. It is worth underlining that in this process for optimal parameters, there is no electrode-tool wear. The main disadvantage of ECM is rather low accuracy, which results from a dissatisfactory dissolution process localization [4]. In electrodischarge machining (EDM), material is removed as a result of phenomena occurring during electrical discharges in the machining area. The main phenomena are material melting and vaporization. The disadvantages of this process are a low metal removal rate, a heat-affected zone on the machined surface, and low surface quality [9]. In this process, there is a critical interelectrode gap thickness for the occurrence of electrical discharges. This is the reason for a significantly higher localization of the machining than in ECM, which makes it possible to achieve significantly higher accuracy of the machined surface than in ECM.

One of the research and development trends in today's micro-manufacturing technology is also the integration of 
different manufacturing techniques into a single machine tool. In this respect, integration is defined as a combination of various manufacturing technologies in a single workstation to obtain a product of high and clearly defined features. Such a solution can be justified by economical or synergetic reasons. In the former, this results in combined or complete machining, and in the latter it leads to the hybrid process.

An example of the first approach is the concept of a combined ECM-EDM process in which the ECM and EDM processes should be applied successively in two stages. If the main aim is to achieve a high metal removal rate in the first stage, the material is removed as a result of the dissolution process (ECM) and in the second stage the final stage dimensions with high accuracy are achieved as a result of electrical discharges (EDM). If the main aim is to achieve high quality of the surface layer then the sequence of applied processes is DM $\rightarrow$ ECM. However, the sequence $\mathrm{ECM} \rightarrow \mathrm{EDM} \rightarrow \mathrm{ECM}$ is also possible, and in this case it is possible to obtain a significantly higher metal removal rate than in EDM which is close to EDM accuracy and close to ECM, i.e., good quality of the surface layer. This concept was checked experimentally and gave satisfactory results [18].

The other solution is the application of hybrid machining processes (HMP). According to the CIRP definition, hybrid manufacturing processes are based on simultaneous and controlled interaction of process mechanisms and/or energy sources/tools that have a significant effect on process performance. These processes can be divided into two groups $[5,6]$ :

- Processes in which machined material is removed as a result of the simultaneous occurrence of different ways of removing material (i.e., electrochemical dissolution and electrical discharges ) or of different energy sources (in this case, the main way of material removal is supported by additional energy, i.e., cutting assisted by laser heating [19], grinding assisted by electrochemical dissolution [22], and ultrasonically assisted electrochemical or electrodischarge machining [15]),

- Processes in which the final result is reached in one operation instead of at least two applied formerly (i.e., it could be a combination of grinding and hardening in one operation [2]; the temperature in the machining area is high as a result of the grinding process, with a higher than usual depth of cutting, and after contact with the coolant the surface layer is hardened).

In case of microcutting, the main problem occurring during machining is related to the size effect [11, 20]. This means that with a decrease of the depth-of-cut, a nonlinear relation between the uncut chip thickness and the cutting forces is observed. The implication of such an effect is an increase in the specific cutting energy (the energy necessary to remove a unit of material volume). The size effect has been observed in many engineering materials, such as in brass, aluminium alloys, steel, or polymethyl methacrylate (PMMA), and is related to material properties (strain and stress) and non-material-related factors (cutting edge conditions and frictional effects) [3]. It can be stated that the occurrence of size effect limits application of the microcutting process to machining parts made of soft materials.

One of the solutions to overcome this problem and to achieve high performance of the microcutting process is to develop a hybrid machining process by introducing an additional energy source in the machining area. The role of the additional energy source is to change the machined material's properties (improve material machinability) or to change the material removal mechanism. An example of successfully applying the first strategy in cutting is thermalassisted machining [19]; the second strategy is the ultrasonic vibration-assisted cutting process [1]. However, solving the problem of supporting the cutting process in the case of microparts manufacturing is not easy. In the case of supporting the cutting process by laser heating, laser radiation can increase the temperature of the machined part and, the same, decrease the mechanical properties. When tool or micropart ultrasonic vibrations are applied, the problem of micropart distortion as a result of vibration can occur. As a result, the micropart can be easily distorted by the cutting forces. From an analysis of processes which can support cutting, it seems that the electrochemical dissolution or passivation process can be applied since it does not introduce additional forces or heat because the above-mentioned electrochemical processes can be carried out in a temperature that is significantly lower than $100^{\circ} \mathrm{C}$.

In this paper, the concept of the electrochemically assisted microturning process will be presented. This is a hybrid process designed in order to improve material machinability. Microcutting directly removes the material, while electrochemical assistance changes the conditions of the cutting by changing the mechanical properties of the machined material. The investigated process is a typical hybrid machining process.

\section{Problem formulation}

The course of electrochemical dissolution process is described by two main characteristics: the Pourbaix diagram and polarization curve. The Pourbaix diagram gives information about stable phases of an aqueous electrochemical system in relation to potential and electrolyte pH. Especially, it can be stated that during the electrochemical process, a thin electrolytic passive film (oxide 
layer) grows on the workpiece surface for the appropriate range of material potential and electrolyte $\mathrm{pH}$. The polarization curve is a relation of current density versus electrode potential, and gives possibility to determine behavior of metal under different electrochemical conditions. Especially for passive systems, when use passive aqueous electrolyte, it shows active, passive, and transpassive states of metal. The transition from active to passive state is characterized by significant decrease of the anodic current density above a critical potential (passivation potential). In this range of potential isolating oxide barrier develops at the interface between electrode and electrolyte and small almost potential independent anodic dissolution current flows between electrode. Beyond the passive potential range, in most of passivable metals, transpassivation occurs with a potential dependent metal dissolution current which is orders of magnitude larger than the passive dissolution current $\left(0.01 \mathrm{~A} / \mathrm{mm}^{2}\right.$ versus $\left.1 \mathrm{~A} / \mathrm{mm}^{2}\right)$. From above results, that proper selection of electrochemical system parameters gives possibility to created stable thin oxide layer on the material.

The idea of electrochemical assistance of the cutting process has been described in $[8,21]$ and is based on the fact that metal has different mechanical properties than its oxide. This layer has properties that are different than the core material and can be removed with the use of a relatively reduced cutting force. An analysis of the technical feasibility of electrochemical assistance leads to the conclusion that straight turning is the most perspective way to verify the concept presented here. This is due to the fact that in straight microturning, electrochemical assistance can take place simultaneously with the cutting process (Fig. 1). It is worth underlining that a decrease in the cutting force is possible when the thickness of the removed material is in the range of thickness of the created oxide layer. Thus, for the

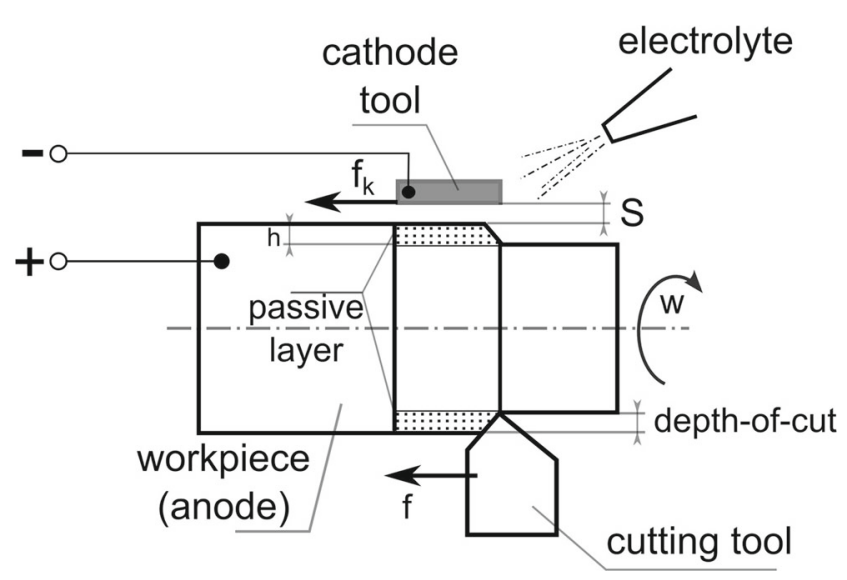

Fig. 1 Scheme of electrochemically assisted microturning process: $S$ interelectrode gap, $h$ thickness of the passive layer, $f, f_{k}$ cutting tool and cathode feed rate $\left(f=f_{k}\right), w$ rotational speed investigated process, the most important characteristic is the relation between the electrochemical assistance parameters and the thickness and mechanical properties of the oxide layer.

The results of the research were to help determine the passive layer thickness, and its mechanical properties were presented in the $[16,17]$. The passive layer was formed on planar surfaces of 1.4301 steel samples with the application of $1 \% \mathrm{NaNO}_{3}$ water solution (electrolyte). The ellipsometry technique was applied to estimate the passive layer thickness. For voltage $U=1$ and $U=3 \mathrm{~V}$, the passive layer thickness did not exceed $100 \mathrm{~nm}$, while for voltage $U=5 \mathrm{~V}$, dissolution of the material took place. The surface topography was also analyzed by an optical profilometer. From the obtained Fourier transforms and roughness distribution results, we know that after passivation the surface changes from an anisotropic state to an isotropic state.

The second part of the research presented in [17] consisted of nanoindentation tests conducted on a Hysitron TI 950 TriboIndenter. The obtained results point to the significant difference in the hardness of the surface layer of samples before and after passivation, especially for load $P_{\max }=10 \mathrm{mN}$. Additionally, the mean depth of tip penetration for the passivated sample was about $150 \mathrm{~nm}$ less than for the substratum sample (200 versus $350 \mathrm{~nm}$ ) for load $P_{\text {max }}=10 \mathrm{mN}$, and for $P_{\text {max }}=100 \mathrm{mN}$ the differences in the depth of tip penetration were negligible. Our measurements show that the passive layer created on the machined surface is harder than the core of the material. This layer is probably also brittle, and because of this, it is easy to remove by the cutting edge. This assumption also results from an analysis of the new process, i.e., electrochemical honing applied to the finishing bevel gears $[13,14]$. This process does not constitute classical electrochemical honing because an abrasive tool is not applied; it is rather an electrochemical-mechanical process in which (Fig. 2):

- A passive layer is created by using the electrochemical process on the tooth surface of the wheel (1).
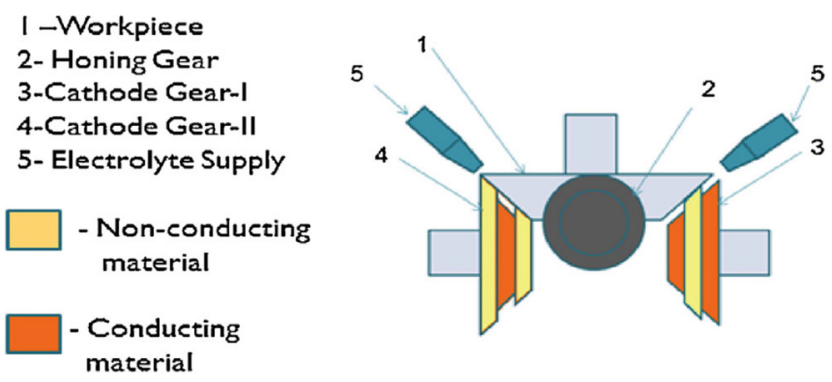

Fig. 2 Scheme of finishing in the hybrid electrochemical-mechanical process of toothed conical wheel $1 ; 2$ - wheel tool (harder than machined wheel 1;3 and 4 - wheels - cathodes with conducted and unconducted parts, 5 - nozzles for the electrolyte supplying [14] 


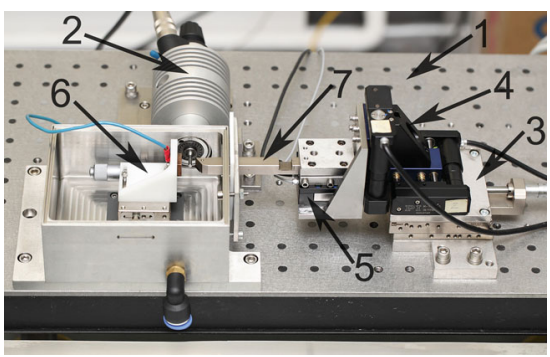

Fig. 3 Photography of a microturning test-stand with marked main parts: working table (1), high speed spindle (2), manual micrometer stage (3), PI M112.DG micro-translation stages (4), piezo nanopositioner PI P-611.1 (5), tooling for electrochemical assistance (6), and tool holder (7)

- The passive layer is removed as a result of mechanical tight cooperation (mesh) of the machined wheel (1) with a harder wheel (2) which is not connected with an electrical source.

Cathode wheels 3 and 4 mesh with wheel 1 on the unconducting parts. Between machined wheel 1 and the copper parts of the cathode wheels, there is a gap $\approx 1 \mathrm{~mm}$. Here, the electrolyte is supplied and the surface of the machined wheel surface is passivated. In some period of time, wheel 1 tightly meshes with wheel 2 (which is harder than wheel 1). Wheel 2 is not connected with an electrical source. After 2 min of such interaction, the passive layer is removed and the surface roughness and accuracy of wheel 1 are significantly increased. If the passive layer on the surface of machined wheel 1 was not brittle enough, it would be impossible to remove it and to improve the quality of the machined wheel. This fact can partly support our explanation of the phenomena occurring during the turning process which is supported by electrochemical passivation of the machined surface.

Based on the literature and on our primary results, it can be stated that the passive layer is harder and more stiff than the substratum layer. In order to verify this conclusion during cutting, experiments on straight turning were carried out. The assumptions and results of these are presented in the following paragraphs.

\section{Test stand design}

The test stand design should include considerations regarding machining allowance of thickness less than $1 \mu \mathrm{m}$ for shafts with a diameter $<1 \mathrm{~mm}$. It is worth underlining that due to electrochemical impact, the test stand was built using corrosive-resistant materials. The main part of the test stand consists of (Fig. 3) a vibroisolated working table; highspeed spindle with max rotation speed of 100,000 rpm; a tool and workpiece motion system (consisting of a manual micrometer stage for initial tool positioning, DC microtranslation stages for tool feed movements and one axis linear piezo nanopositioner for the main cutting movement); tooling for electrochemical assistance; and system for cutting force analysis based on the strain gauge force sensor.

The data acquisition system for main cutting force measurement in microturning consists of hardware components (force sensor CL 17pm, CL 10D amplifier and the NI USB-6351 data acquisition unit) and a LabView platform with developed software for data acquisition and storage. It allows allows to measure force in a range of $0-5 \mathrm{~N}$ with an accuracy of $2.5 \mathrm{mN}$. Registered force signals were analyzed with DIAdem and Matlab software. The force sensor was mounted on a tool holder (Fig. 4), which allowed to measure the thrust of the holder on the force sensor in the direction of the main cutting force. The measured value is proportional to the main cutting force $F_{c}$. It is worth underlining that the main research goal was to determine the difference between the traditional and the electrochemically assisted microturning process and, in this case, such a solution is sufficient.

The force sensor was calibrated by the producer; however, it was mounted on the tool holder which, during machining with electrochemical assistance, was connected
Fig. 4 Scheme showing the method of mounting the strain gauge force sensor CL $17 \mathrm{pm}$

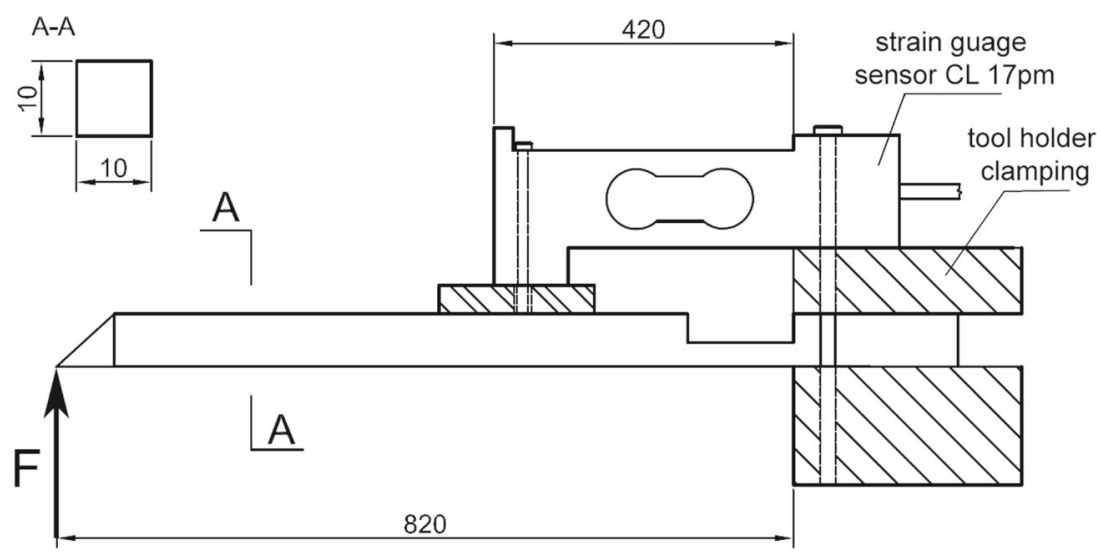




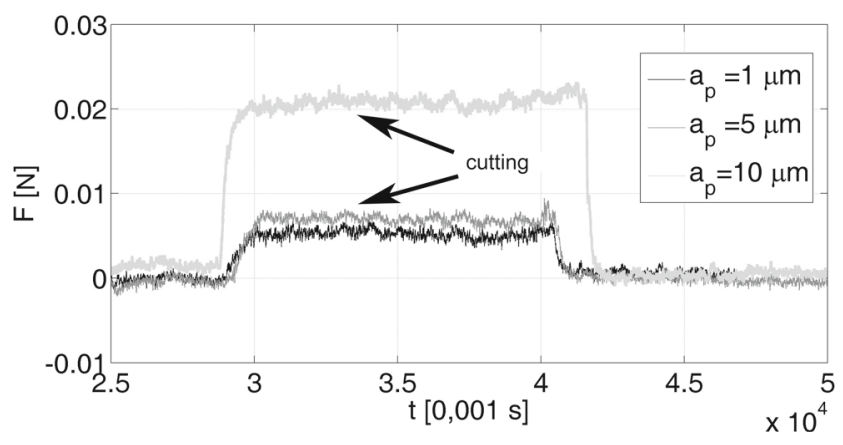

Fig. 5 Force signal for straight turning with three different values of $a_{p}$; other cutting parameters: $v_{c}=80 \mathrm{~m} / \mathrm{min}$, feed rate $f=3 \mu \mathrm{m} / \mathrm{rev}$

to positive voltage (the same potential as the shaft-anode). Therefore, in order to identify an exclude this voltage impact on force sensors characteristics under additional voltage ( $U=3 \mathrm{~V}$ and $U=10 \mathrm{~V}$ ) connected to the hausing was determined. The obtained relations between sensor load and amplifier output voltage are highly linear, with coefficient of determination $R^{2}=0.998$, thus it can be stated that the interelectrode voltage has no influence on the measurement results.

Verification of the described method of force measurement was carried out for straight turning (oblique cutting) with three different values of depth of cut $a_{p}$ equal to 1 , 5 , and $10 \mu \mathrm{m}$. It can be stated that the values of the sensor load are in the range of milinewtons. From a comparison of the force signals (Fig. 5), it turns out that the sensor load decreases nonlinearly with the depth of cut $a_{p}$, which is in agreement with the cutting process scaling effects [20].

\section{Experimental investigation}

\subsection{Research methodology}

The main goal of the research was to determine the effect of electrochemical assistance on microcutting process. Therefore, straight turning research tests were carried out. The research was conducted according to the theory of the experiment with the following input parameters

- cutting speed $v_{c}: 40-120 \mathrm{~m} / \mathrm{min}$

- feed rate $f: 1-5 \mu \mathrm{m} / \mathrm{rev}$.

The depth of cut $a_{p}$ was assumed as constant and equal to $1 \mu \mathrm{m}$, which resulted from research on passive layer thickness [17] and with the conclusion that passive layer thickness is less than $1 \mu \mathrm{m}$, therefore, electrochemical assistance cannot be justified for higher values of $a_{p}$. The cutting was carried out with the tungsten carbide Mitsubishi turning insert DCET070200R-SN NX2525 and 1.4301 stainless steel (shaft with diameter $2.9 \mathrm{~mm}$ ) was selected as the machined material. The shaft diameter was far from the micromachining domain and such a value was assumed intentionally in order to facilitate the force measurement. However, the assumed depth of cut was in the range of microcutting. The electrochemical assistance parameters were as follows:

- interelectrode voltage $U=3 \mathrm{~V}$,

- initial interelectrode gap thickness $S=0.25 \mathrm{~mm}$,

- electrolyte: $1 \%$ water solution of $\mathrm{NaNO}_{3}$.

Taking into account cathode dimensions, it gives current density in range of $0.01 \mathrm{~A} / \mathrm{mm}^{2}$. Each test consisted of removing ten layers of material without electrochemical assistance and then, on the same shaft, another ten layers of material was removed with electrochemical assistance. A new cutting tool was applied for each test. During the tests, the force signal was registered, smoothed, and then

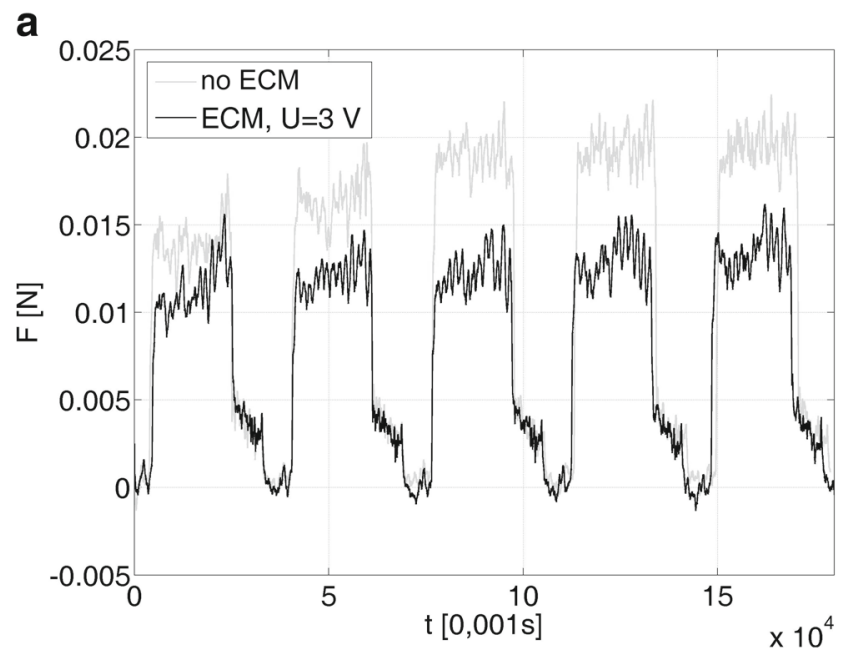

b

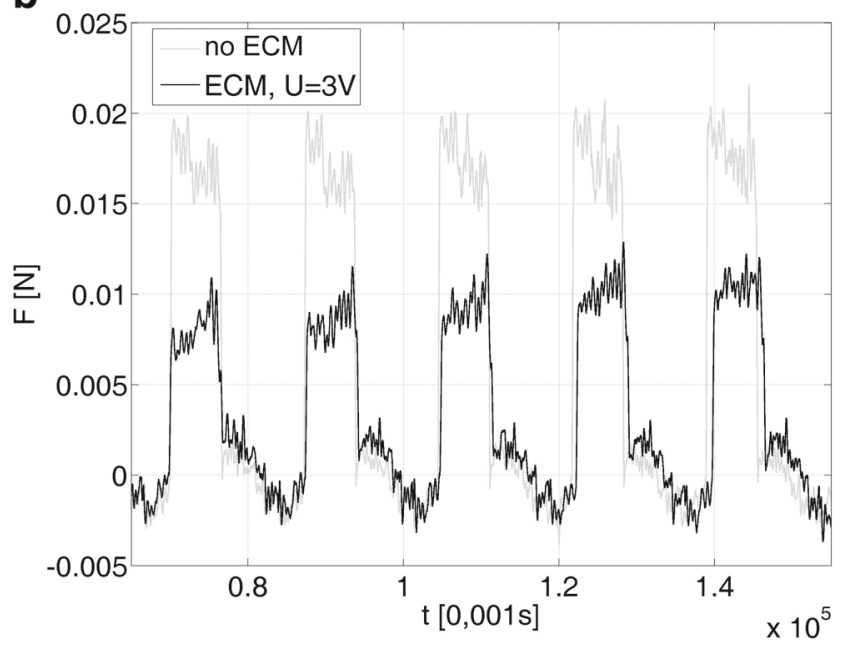

Fig. 6 Relation of force sensor load during cutting with the following parameters: feed rate $f=3 \mu \mathrm{m} / \mathrm{rev}$, cutting speed: $v_{c}=40 \mathrm{~m} / \mathrm{min}(\mathbf{a})$, $v_{c}=120 \mathrm{~m} / \mathrm{min}(\mathbf{b})$ 
analyzed. The difference $\Delta F$ between the average forces (calculated from ten tool passes) during normal and assisted turning was selected as the main output parameter.

\subsection{Results discussion}

As was presented in Fig. 6, the influence of electrochemical assistance has a significant effect on the sensor load during machining. Generally, it causes a decrease in the cutting force; however, the sensor load decrease depends on the investigated cutting parameters: cutting speed $v_{c}$ and feed rate $f$. With increase of $v_{c}$, the tool wear increases what also cause sensor load increase. Therefore, for $v_{c}=120 \mathrm{~mm} / \mathrm{min}$ and $f=1 \mu \mathrm{m} / \mathrm{rev}$ the greatest benefits of electrochemical assistance are observed.

Figure 7 presents the relations of the average cutting force decrease $\Delta F$ (relative and absolute) resulting from the application of electrochemical assistance. It can thus be stated that electrochemical assistance causes a decrease in the average cutting force from a few to several milinewtons, which in relation to the force value gives a few to several percent. Cutting of harder and brittle layer lead to change of machining conditions. Plastic deformation of austenitic stainless steel are connected with strengthening mechanisms what results in increase of cutting force and tool wear. This effects is particularly noticeable when depth of cut is small. Created during electrochemical passivation oxide layer has significantly higher reduced Young's modulus, higher hardness what cause, that share of plastic deformation during cutting is reduced and material strengthening is decreased. For the investigated range of cutting parameters, electrochemical assistance is the most beneficial for feed rate $f=1 \mu \mathrm{m} / \mathrm{rev}$, and with $f$ increase the impact of assistance becomes insignificant (for higher values of feed rate $\Delta F$ is

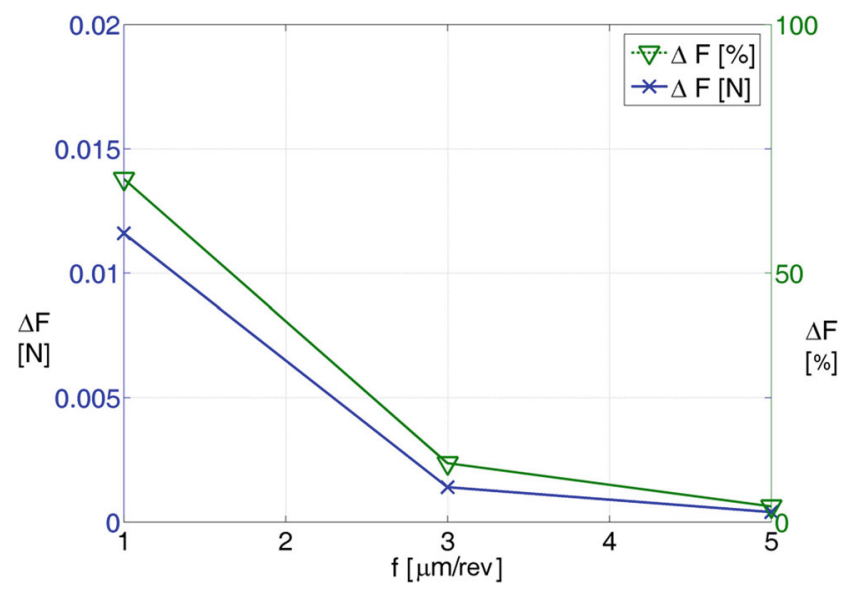

Fig. 7 Influence of electrochemical assistance on a decrease (relative and absolute) in the average cutting force, relation from feed rate $f$; other cutting parameters: depth of cut $a_{p}=1 \mu \mathrm{m}$, cutting speed $v_{c}=80 \mathrm{~m} / \mathrm{min}$

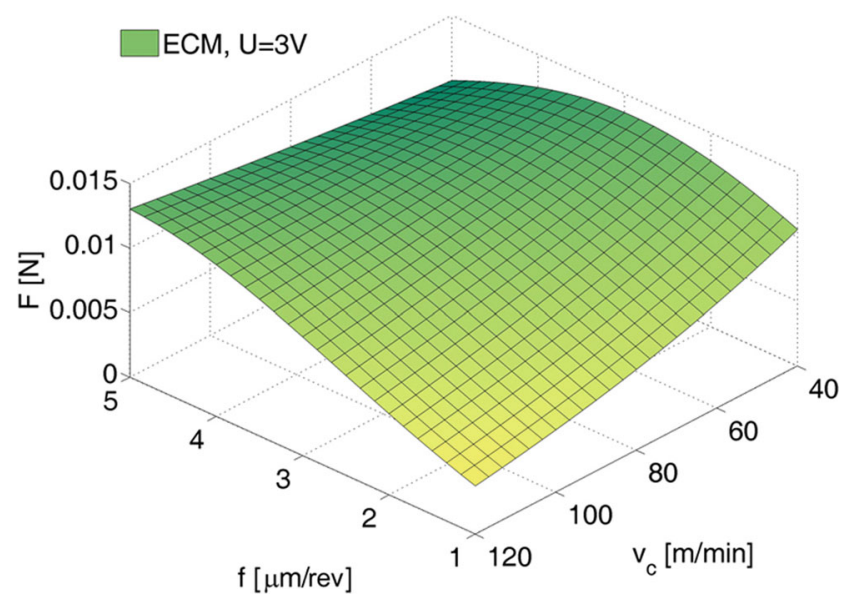

Fig. 8 Relationship of sensor load from cutting speed $v_{c}$ and feed rate $f$; machining with electrochemical assistance

at the level of measurement error). A smaller feed means smaller chip thickness and force increase (for $f=1 \mu \mathrm{m} / \mathrm{rev}$, $F=0.0168 \mathrm{~N}$, and $f=5 \mu \mathrm{m} / \mathrm{rev}, F=0.0128 \mathrm{~N}$ ), and also longer time of tool work. It can be concluded that electrochemical assistance gives benefits when the undeformed chip thickness is in the range of passive layer thickness (significantly less than $1 \mu \mathrm{m}$ ).

The relation $F_{E C M}\left(v_{c}, f\right)$ and $\Delta F\left(v_{c}, f\right)$ was approximated with the assumption of a full quadratic (constant, linear, interaction, and squared terms) polynomial as a response surface. Matlab software was used to calculate the polynomial coefficients and to perform regression analysis. The analysis of the obtained polynomials (Figs. 8 and 9) leads us to the conclusion that the most benefits of electrochemical assistance are for $f<2 \mu \mathrm{m}$.

Figure 10 presents the SEM photographs of the working tool surfaces. It can be stated that the main types of

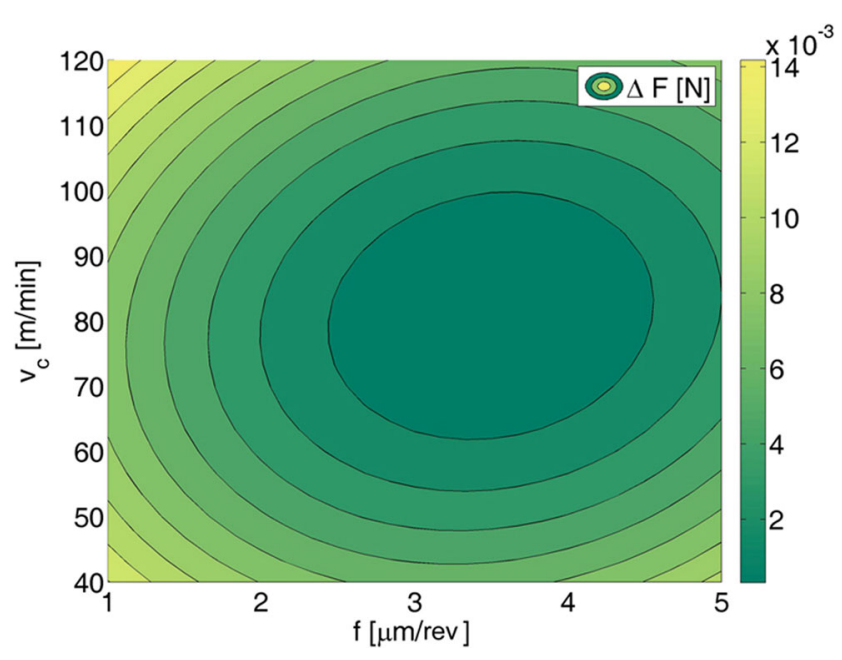

Fig. 9 Contour map of the sensor load decrease $\Delta F$ due to electrochemical assitance from cutting speed $v_{c}$ and feed rate $f$ 

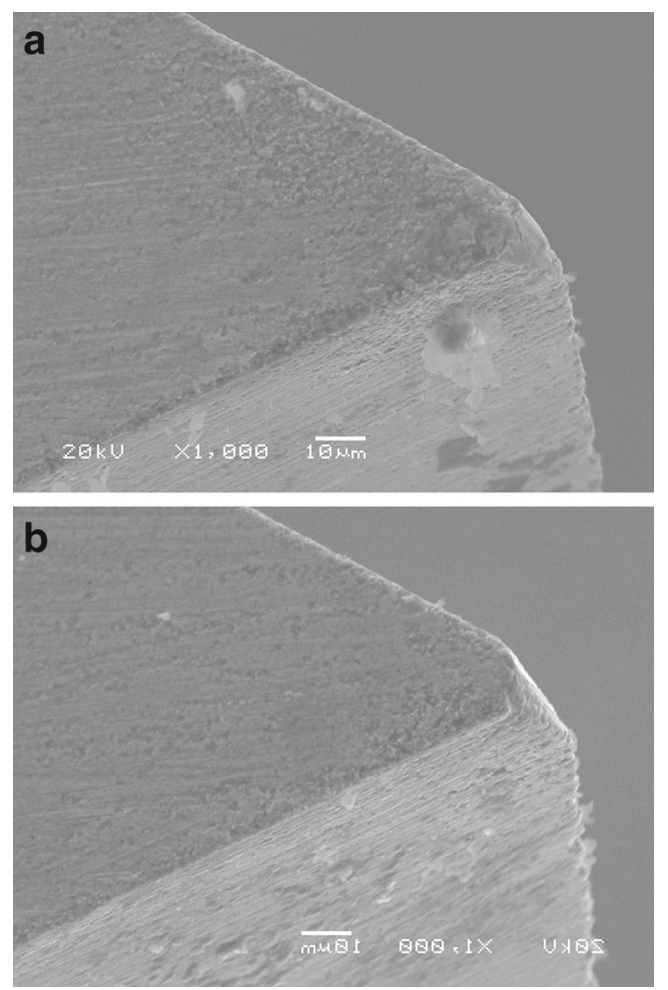

Fig. 10 SEM photographs of the cutting edge after removing 10 layers of material with the following cutting parameters: depth of cut $a_{p}=1 \mu \mathrm{m}$, cutting speed $v_{c}=80 \mathrm{~m} / \mathrm{min}$, feed rate $f=3 \mu \mathrm{m} / \mathrm{rev}$; (a) machining without electrochemical assistance, (b) machining with electrochemical assistance

wear are abrasive and adhesive wear, and based on the qualitative analysis, we can conclude that applying of electrochemical assistance causes a slight decrease in tool tip and main cutting edge wear. Also electrochemical etching on the working surfaces does not take place.

To confirm that the concept presented here can bring benefits, we conducted primary research on electrochemical assistance in the micro-cutting process. A qualitative comparison of the process without and with electrochemical assistance was conducted based on SEM photographs (Fig. 11). On the surface that was machined using traditional cutting, areas with plastic deformation can be observed, which indicates the ploughing effect during machining. A surface machined with electrochemical assistance indicates cutting condition changes due to a change in the machined material properties (the machining parameters were the same in both cases). In case of micromachining by cutting during material removal, two mechanism dominate [7]: chip removal and ploughing. When depth of cut is in range of minimum chip thickness (as uninvestigated case), the ploughing effect plays significant role in material removal mechanism [7]. This applies in particular when machining ductile materials as investigated 1.4301 stainless steel. a
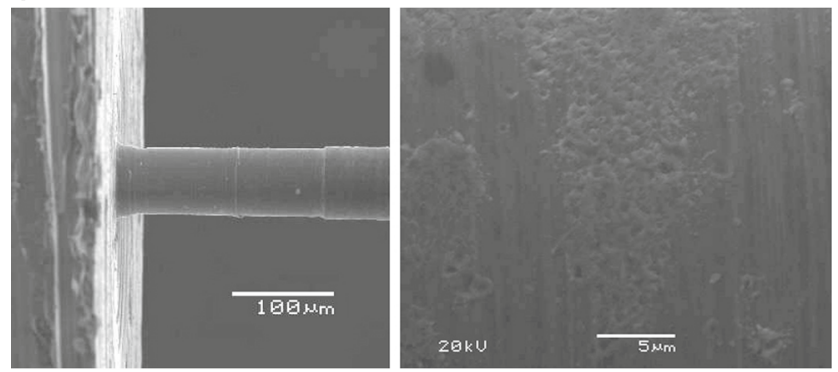

b
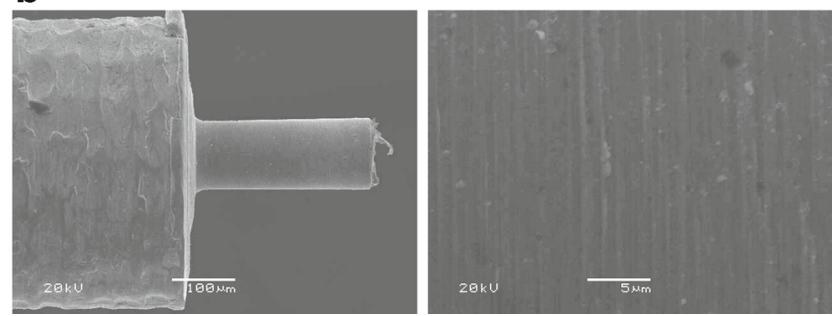

Fig. 11 SEM photographs of the shaft and its surface layer after microturning without (a) and with electrochemical assistance (b); machined material: 1.4301 steel, depth-of-cut $a_{p}=1 \mu \mathrm{m}$, feed $f=$ $0,02 \mu \mathrm{m} / \mathrm{s}$, rotation speed $600001 / \mathrm{min}$ (for $d=100 \mu \mathrm{m}$ this gives $\left.v_{c}=20 \mathrm{~m} / \mathrm{min}\right), U=3 \mathrm{~V}$, electrolyte $1 \% \mathrm{NaNO}_{3}$

Machining of brittle and harder oxide layer gives possibility to decrease of ploughing effect, because properties of machined layer are close to fragile material.

\section{Conclusions}

The paper presents the concept of electrochemical assistance of the microcutting process. It can be stated that investigated process is a hybrid machining process in which the microcutting directly removes the material while electrochemical passivation changes the conditions of cutting (removing of changed by electrochemical assistance material gives possibility to decrease adverse influence of ploughing on cutting force.) The literature review and the authors' primary results show that the passive layer is harder and more stiff than the substratum layer. Therefore, experiments on straight turning were carried out in order to verify this conclusion during cutting. For this purpose, a test stand and a system to analyze the cutting force were both designed and built. The goal of the experiment was to obtain a relation between the cutting speed and the feed rate on the main cutting force when machining without and with electrochemical assistance. It was then possible to obtain the change of the main cutting force resulting from electrochemical assistance. Electrochemical assistance caused a decrease in the average cutting force from a few to several milinewtons, which in relation to the force value gives a few to several percent. Results analysis led to the conclusion 
that for the investigated range of cutting parameters, electrochemical assistance is the most advantageous for feed rate $f=1 \mu \mathrm{m} / \mathrm{rev}$, and that the impact of assistance becomes insignificant along with feed increase.

To confirm that the concept presented here can bring benefits during the part shaping process, we performed primary tests on electrochemical assistance in the straight microturning process. Areas with plastic deformation can be observed (ploughing effect during machining) on the surface machined using traditional cutting, while the surface machined with electrochemical assistance indicates cutting condition changes due to a change of the machined material properties (the surface quality was improved). It is also worth underlining that the application of electrochemical assistance caused a slight decrease in tool tip and main cutting edge wear and that no electrochemical etching on the working surfaces could be formulated.

The research presented here shows the potential benefits of electrochemical assistance during cutting. However, the limitations of hybrid machining as presented in this paper should be underlined; these include a limited range of materials (only passivating metals or alloys such as aluminium, stainless steel, or titanium alloys could be machined) and limited efficiency (electrochemical assistance brings benefits when the depth-of-cut is $\leq 1 \mu \mathrm{m}$ ). Therefore, electrochemical assistance during cutting should be applied as the final stage of microparts machining.

Acknowledgments The financial support of the polish National Science Centre is gratefully acknowledged (grant no. 2152 /B/T02/ 2011/40)

Open Access This article is distributed under the terms of the Creative Commons Attribution 4.0 International License (http:// creativecommons.org/licenses/by/4.0/), which permits unrestricted use, distribution, and reproduction in any medium, provided you give appropriate credit to the original author(s) and the source, provide a link to the Creative Commons license, and indicate if changes were made

\section{References}

1. Brehl DE, Dow TA (2008) Review of vibration-assisted machining. Precis Eng 32:153172

2. Brockhoff T, Brinksmeier E (1999) Grind-hardening: a comprehensive view. CIRP Ann - Manuf Technol 48(1):255-260

3. Cheng K, Huo D (eds) (2013) Micro-cutting: fundamentals and applications. Wiley
4. Davydov AD, Volgin VM, Lyubimov VV (2004) Electrochemical machining of metals: fundamentals of electrochemical shaping. Russ J Electrochem 40(12):1230-1265

5. Lauwers B (2011) Surface integrity in hybrid machining processes. Procedia Eng 19:241-251

6. Lauwers B, Klocke F, Klink A, Tekkaya AE, Neugebauer R, Mcintosh D (2014) Hybrid processes in manufacturing. CIRP Ann Manuf Technol 63(2):561583

7. Liu X, DeVor RE, Kapoor SG, Ehmann KF (2004) The mechanics of machining at the microscale: assessment of the current state of the science. J Manuf Sci Eng 126(4):666-678

8. Nagata M, Wakabayashi K, Yamada M, Masuzawa T (1999) Microcutting with reduced cutting force by electrolysis. J Jpn Soc Electr Mach Eng 33(74):24-31

9. Pham DT, Dimov SS, Bigot S, Ivanov A, Popov K (2004) Microedm - recent developments and research issues. J Mater Process Technol 149:50-57

10. Rajurkar KP, Sundaram MM, Malshe AP (2013) Review of electrochemical and electrodischarge machining. Procedia CIRP 6:13-26

11. Ramos AC, Autenrieth H, Strau T, Deuchert M, Hoffmeister J, Schulze V (2012) Characterization of the transition from plugging to cutting in micro machining and evaluation of the minimum thickness of cut. J Mater Process Technol 212(3):594-600

12. Ruszaj A, Skoczypiec S (2012) Combine electrochemical and electrodischarge microdetails shaping. In: Shore P, Spaan H, Bur $\mathrm{T}$ (eds) Proceedings of the 12th international conference of the European society for precision engineering and nanotechnology, vol 2, Stockholm, pp 516-519. euspen Headqarters

13. Shaikh JH, Jain NK (2014) Modeling of material removal rate and surface roughness in finishing of bevel gears by electrochemical honing process. J Mater Process Technol 214:200-209

14. Shaikh JH, Jain NK (2015) Effect of finishing time and electrolyte composition on geometric accuracy and surface finish of straight bevel gears in ech process. CIRP J Manuf Sci Technol 8:53-62

15. Skoczypiec S (2011) Research on ultrasonically assisted electrochemical machining process. Int J Adv Manuf Technol 52:565574. $24 \mathrm{pkt}$

16. Skoczypiec S, Grabowski M, Ruszaj A (2013) Primary research on electrochemical assistance of microcutting process. In: Proceedings ot the 13th international conference of the European society for precision engineering and nanotechnology, vol II. EUSPEN, Berlin, pp 261-264

17. Skoczypiec S, Grabowski M, Spychalski M (2014) Experimental research on elelctrochemically asssisted microturning process. Key Eng Mater 611-612:701-707

18. Skoczypiec S, Ruszaj A (2014) A sequential electrochemicalelectrodischarge process for micropart manufacturing. Precis Eng 38:680690

19. Sun S, Brandt M, Dargusch MS (2010) Thermally enhanced machining of hard-to-machine materials a review. Int $\mathrm{J}$ Mach Tools Manuf 50:663680

20. Vollertsen F, Biermann D, Hansen HN, Jawahir IS, Kuzman K (2009) Size effects in manufacturing of metallic components. CIRP Ann - Manuf Technol 58(2):566-587

21. Wakabayashi K, Kawamata S, Yamada M, Tanaka T, Nagata M (1999) Micro cutting method and systems

22. Zhu D, Zeng YB, Xu ZY, Zhang XY Precision machining of small holes by the hybrid process of electrochemical removal and grinding. CIRP Ann - Manuf Technol:247250 